\title{
Scientific mapping of the knowledge on the El Cielo Biosphere Reserve
}

\author{
Caballero-Rico, Frida Carmina ${ }^{1}$ \\ ${ }^{1}$ Universidad Autónoma de Tamaulipas, Centro de Excelencia. Cd. Victoria, Tamaulipas, México. \\ * Corresponding author: fcaballer@uat.edu.mx
}

Gitation: Caballero-Rico, F. C. (2021)

Scientific mapping of the knowledge

on the El Cielo Biosphere Reserve.

Agro Productividad, 14(\#). https://doi.

org/10.32854/agrop.v14i7.1879

Editor in Chief: Dr. Jorge Cadena Iñiguez

Estimated publication date: August 2021

This work is licensed under a Creative Commons Attribution-Non-Commercial 4.0 International license.

\section{(i) \$}

\begin{abstract}
The current knowledge of the El Cielo Biosphere Reserve (CBR), Tamaulipas, Mexico was identified from scientific publications between 1993 and 2019.

Objective: Analyze, synthesize and categorize the published research on the El Cielo Biosphere Reserve (CBR), Tamaulipas.

Design/methodology/approach: The methodology focused on searching, classifying and reviewing existing sources in the SCOPUS database from a knowledge base perspective. The assessment recovered 37 publications that were analyzed and mapped in four dimensions: size, time, space, and composition. The analyzes were performed using the Bibliometrix and Biblioshiny software tools.

Results: The reviewed publications addressed biodiversity studies from a disciplinary approach and from an ecological perspective, which produces a fragmented knowledge of this territory and its problems.

Limitations on study/implications: There may be publications not appearing in the Scopus database.

Findings/conclusions: The knowledge of the El Cielo Biosphere Reserve is fragmented, with a disciplinary approach and from an ecological perspective. The lack of a critical mass of researchers to generate useful knowledge is observed. A weak intellectual structure is also found, which generates a reduced contribution to the conservation of biodiversity. The original contribution of this paper is the synthesis of the current state of the knowledge regard biodiversity and conservation of the El Cielo Biosphere Reserve, which had not been performed previously.
\end{abstract}

Keywords: Science Mapping, Knowledge basis, Knowledge management, El Cielo Biosphere Reserve.

\section{INTRODUCTION}

The effective conservation of biodiversity is based on knowledge and understanding of ecological patterns and processes (Fischer \& Lindenmayer, 2007; Fahrig et al., 2011; Tscharntke et al., 2012). However, research such as that from Giehl et al. (2017) documents there is no reliable information on the available scientific knowledge, or if this is used to design conservation processes. Hallinger \& Suriyankietkaew (2018) point out that the analysis of the knowledge basis can be done in four dimensions: size, time, space and composition. Size is the volume of accumulated knowledge. The productive knowledge 
accumulation requires a critical mass of research and a long time must pass before a discipline or field accumulates a sufficient body of knowledge. Therefore, knowledge size is necessary but an insufficient precondition for a useful knowledge base (Hallinger \& Suriyankietkaew, 2018). In this context, according to Richardson (2013), the accumulation of knowledge is a dynamic process that changes over time. Time refers to the paths that a publication follows within a discipline or research line. Meanwhile, space refers to the geographical distribution of documents within a knowledge base. The spatial distribution offers information on academic ability and reveals concentrations and gaps in the production and knowledge accumulation in different societies (Hallinger \& Suriyankietkaew, 2018).

The composition of the intellectual structure of the knowledge basis is the fourth dimension. It allows identifying gaps, orientations, structures and patterns of the research, thus exposing how the study of a territory and the development of knowledge are approached (Topp \& Loos, 2019). In this regard, Gazni et al. (2012), Khasseh et al. (2017), Wagner et al. (2017), and López \& Sassone (2019) point out that the studies are carried out at a country level and it is necessary to be complemented with what happens in each protected natural areas (PNA), given that these represent specific situations that must be addressed to ensure their conservation. In this sense, it should be noted that no previous studies were found in a PNA in Tamaulipas, Mexico.

The central axis of this research was to analyze, synthesize and categorize the published research from the El Cielo Biosphere Reserve (CBR), Tamaulipas, Mexico. Two characteristics distinguish this review: it is a first on the produced knowledge, and second, its "scientific mapping" used (Zupic \& Čater, 2015), a research review method designed to synthesize patterns on the knowledge production within a discipline, rather than synthesizing substantive findings.

For this, four research questions were posed: 1) What is the size, growth trajectory and distribution of the literature on CBR?, 2) What are the topics studied by academics in the CBR area?, 3) What journals have been used by the authors to disseminate their findings?, and 4) What is the intellectual structure of the CBR knowledge base?

In this research structure, in the first place are the antecedents that include aspects of relevant knowledge generation for this research and the previously reported work in the literature. Subsequently, the methodology used for this study is described. Then the obtained results and their discussion are presented. Finally, the main conclusions of the research and future works established that follow up on the research topic are presented.

\section{MATERIALS AND METHODS}

To analyze the scientific production on the GBR, the research results described in scientific papers, book chapters and reviews were assessed. A retrospective quantitative analysis was performed based on the articles published in the Scopus database (https:// www.scopus.com). For its identification, the combination of the words "Reserva Biosfera El Cielo Tamaulipas México - Biosphere Reserve El Cielo Tamaulipas Mexico” was used. The search took place on March 18, 2019. The search date range of the publications was open. The initial documents selection eliminated ineligible source types (research that cited work done in the GBR or only mentioned it as a context) and duplicate elements. 
First, the searches were done for all fields, later, it was carried out by article title, abstract and keywords, to ensure that the articles belonged to the CBR, leaving 37 articles. The first was published in 1993, so the investigation period comprises from 1993 to March 2019, that is, 26 years. For the analysis of these 37 papers, the associated bibliometric data was downloaded from Scopus in BIBX format, the extracted metadata included the authors' names, affiliation information, year of publication, keywords, abstracts, and various citations information. Later, analyzed with the Bibliometrix package through the Biblioshiny application, both implemented in the $\mathrm{R}$ statistical software environment $(\mathrm{R}$ CoreTeam, 2016).

Descriptive techniques were used to determine the size, growth trajectory and geographic distribution of the publications and to document the main characteristics of the knowledge base on the GBR. Regarding the bibliometric analysis, a citation analysis was applied to evaluate the impact and influence of the authors and documents. The citation analysis examines the direct impact of the documents included in the review database by calculating the number of times each document or author has been cited by other documents located in the Scopus index. Lotka's law (Lotka, 1926; Urbizagastegui, 1999) was used to group authors according to their productivity. While identifying the core publications, Bradford's law (East, 1983; Alvarado, 2016) was used to identify both cases, the most productive researchers and the most relevant journals in this field of study.

\section{RESULTS AND DISCUSSION}

The results were organized around the four research questions laid at the beginning of the research.

\section{Size, growth path, and distribution of the literature on the CBR}

The knowledge database is made up of 37 publications, published between 1993 and 2019 and represents a reduced set of knowledge, not generated in a systematic manner.

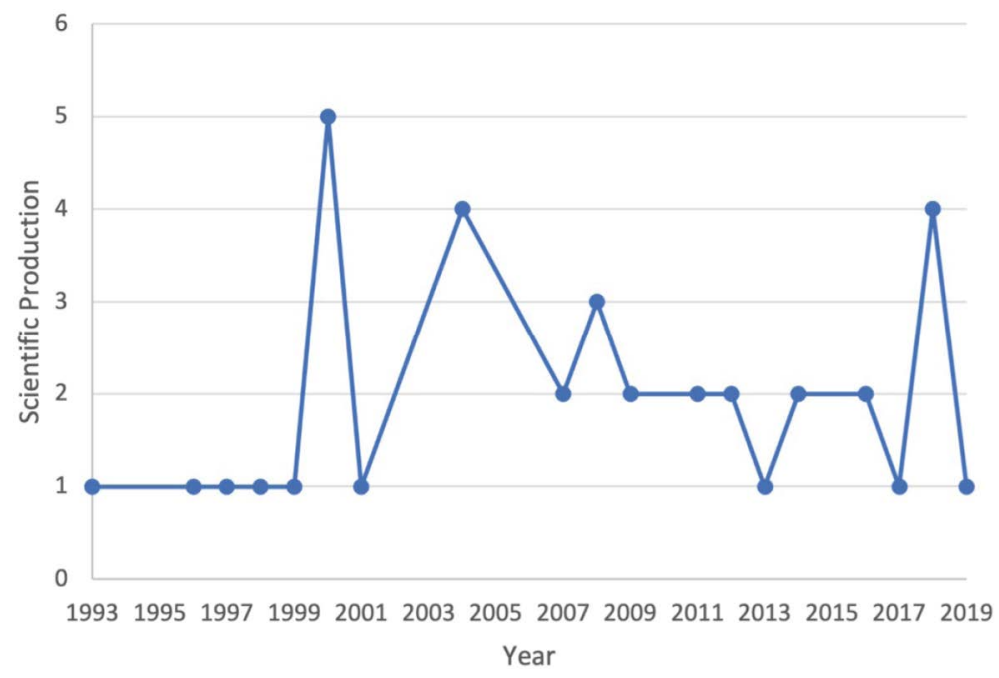

Figure 1. Distribution of the existing literature on the El Cielo Biosphere Reserve between 1993 and 2019. 
The main type of published document was as scientific articles and constitutes $94.59 \%$ of the production. The remaining $5.41 \%$ was made up of a book chapter and a review.

\section{Topics studied by academics in the area of CBR}

The most researched topic was its plant community. Twenty publications were identified, followed by 12 on their animals. There is one on mushrooms and four addressing cross-cutting issues. Figure 2 shows the topics addressed overtime in the analyzed publications.

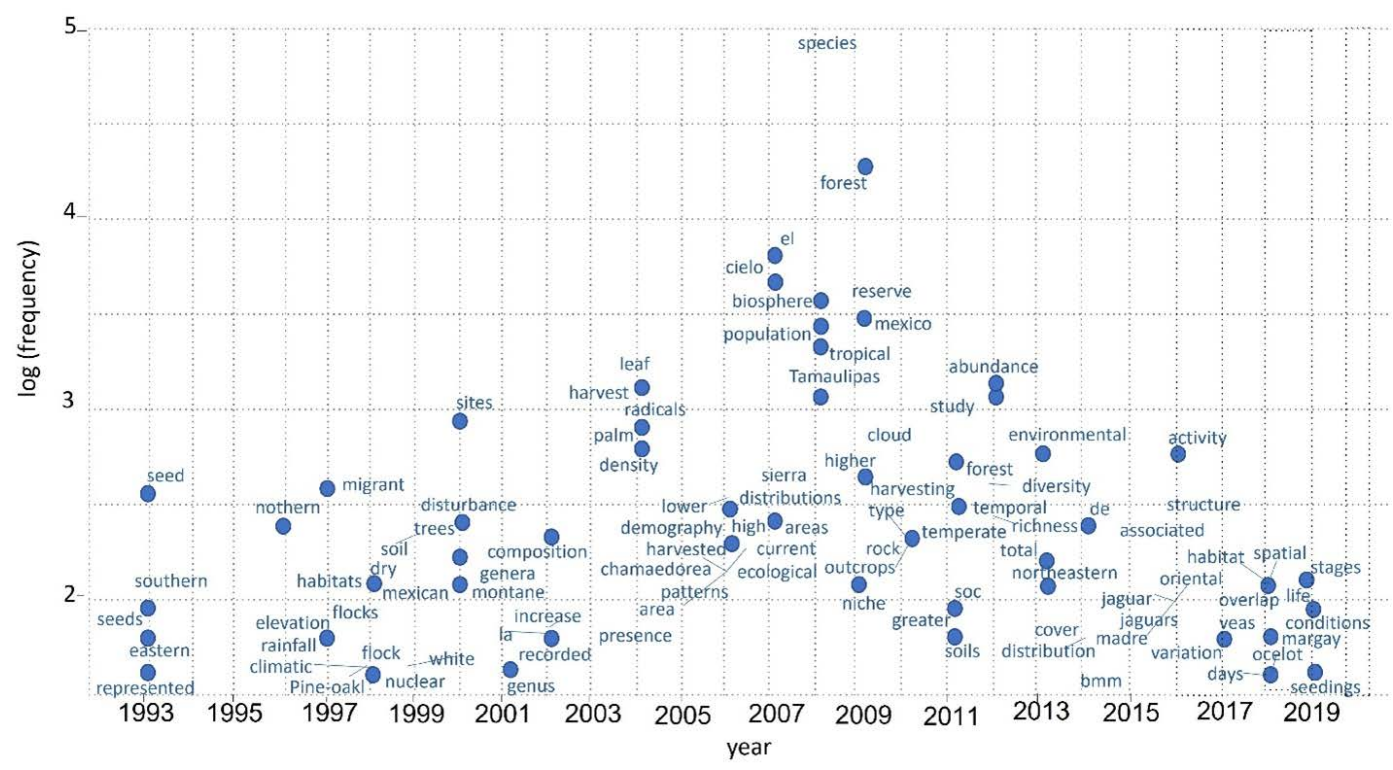

Figure 2. Evolution of the investigated topics on the CBR between 1993 and 2019.

\section{Analysis of influential journals, authors and documents}

This research question inquired about the composition of the knowledge database from the perspective of their sources, academics, and documents. The assessed papers were found to be published in 28 journals. The impact of the chosen journals on which the research results on the CBR were published was determined based on the $h$-index, which defines the quality based on the number of citations a scientific article receives (Hirsch, 2005), finding that the most important is Journal of Tropical Ecology of the USA (Figure 3).

The most cited source in the list of reference publications in Ecology with 79 citations, followed by Conservation Biology with 48. Both journals are published in the USA. With bibliometric analysis, key scholars and documents within a research field can be identified. In this sense, based on Bradford's law, five core journals were identified, the most relevant being: the Journal of Tropical Ecology from England, Southwestern Naturalist and Condor from USA, the Revista de Biología Tropical from Costa Rica, and the Revista de Geofisica from Mexico. 

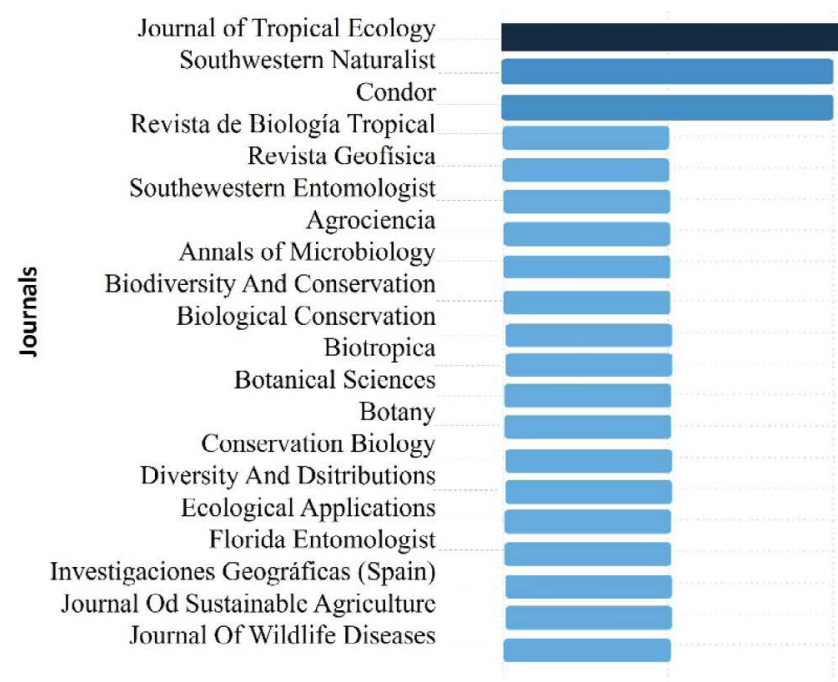

$0 \quad 1$

\section{2}

h-index 3

4

Figure 3. Impact of the journals ( $h$-index) chosen to publish research on the CBR between 1993 and 2019.

In the 37 publications on the CBR from 1993 to 2019, 90 authors participated (Figure 4), the most important authors with their publications and citations, where the size of the circles is proportional to the number of documents published in that year, while the color intensity relates to the total of citations per year.

As can be seen, Gorchov DL is the researcher with the highest production (eight articles) and the highest number of citations, followed by Edress B. (five), both from the USA. The Miami University of Ohio State in the USA is the institution from which the largest number of publications were produced. The total number of citations in the analyzed documents was 599. Their highest number was 248 and reported during 2004.

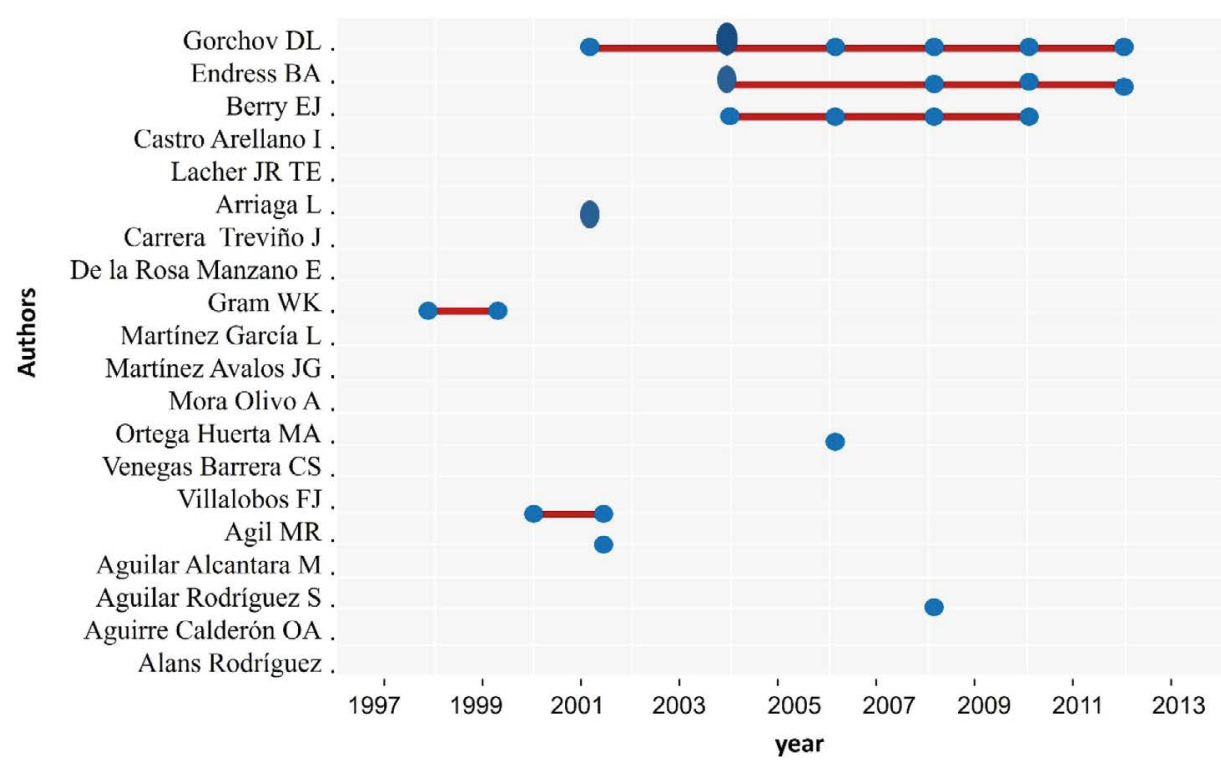

Figure 4. Most relevant authors with their publications and citations. 
The analysis of the most relevant documents, presented in Table 1, referring to the most globally cited documents. The data presented should be interpreted in light of two considerations: most of the most cited researchers publishing on the GBR have a low actual level of Scopus citations, and none is identified as leading worldwide. These findings, therefore, reaffirm that the knowledge base is incipient.

Table 1. Documents most cited worldwide.

\begin{tabular}{l|c|c}
\hline \multicolumn{1}{c|}{ Source } & Total cited & Total cited per year \\
\hline Ortega-Huerta MA, 2004, Diversity Distrib & 103 & 6.0588 \\
\hline Rojas-Soto OR, 2012, Biodiversity Conserv & 62 & 6.8889 \\
\hline Endress BA, 2004, Ecol Appl & 62 & 3.6471 \\
\hline Endress BA, 2004, Conserv Biol & 58 & 3.4118 \\
\hline Gram WK, 1997, Condor & 32 & 1.3333 \\
\hline Gram WK, 1998, Condor & 32 & 1.3913 \\
\hline Berry EJ, 2004, J Trop Ecol & 25 & 1.4706 \\
\hline Arriaga L, 2000, J Trop Ecol-a & 25 & 1.1905 \\
\hline Berry EJ, 2008, Popul Ecol & 21 & 1.6154 \\
\hline Castro-Arellano I, 2009, J Trop Ecol & 20 & 1.6667 \\
\hline Castro-Arellano I, 2008, J Wildl Manage & 19 & 1.4615 \\
\hline Arriaga L, 2000, J Trop Ecol & 18 & 0.8571 \\
\hline Williams-Linera G, 1993, J Trop Ecol & 17 & 0.6071 \\
\hline Castro-Arellano I, 2009, J Wildl Dis & 13 & 1.0833 \\
\hline Berry EJ, 2007, Biotropica & 11 & 0.7857 \\
\hline Ortega Huerta MA, 2007, Biol Conserv & 11 & 0.7857 \\
\hline Jones FA, 2000, Southwest Nat & 11 & 0.5238 \\
\hline Jones RW, 2012, Rev Mex Biodiversidad & 7 & 0.7778 \\
\hline Gruz-Flores G, 201 1, Agrociencia & 6 & 0.6 \\
\hline Ramos-Garza J, 2016, Ann Microbiol & 5 & 1 \\
\hline
\end{tabular}

\section{Intellectual structure of the GBR knowledge base}

An approach that has been used in scientific mapping was applied on the author and co-citation analysis (ACA). Table 2, on the summary of countries with several publications with national and foreign authors, includes the number of publications with at least one foreign author $(M C P=$ Multiple Country Publication $)$ as well as the number of publications that have national authors $(S C P=$ Single Country Publication $)$. The value of the MCP rate is a measure of the intensity of the international collaboration of each country. It can be seen that researchers mainly collaborate with institutions in their own countries.

The geographical distribution of the scientific production by country is presented in Figure 5, where it is observed that Mexico and the USA are the countries that publish the most on the CBR. In the map colors, a strong intensity indicates a lot of academic production while a light intensity represents little. In this sense, Mexico registered 48 coauthors, the USA 35, and Germany and Spain one. The citations contained in the 
articles are concentrated in three countries: USA with 308 citations, Mexico with 208 and Antigua with 65.

Table 2. Summary of countries with the number of publications with national and foreign authors.

\begin{tabular}{l|c|c|c|c}
\hline Country & $\begin{array}{l}\text { Number of } \\
\text { publications }\end{array}$ & $\begin{array}{l}\text { Publications with national authors } \\
(\boldsymbol{S C P}=\text { Single Country Publications })\end{array}$ & $\begin{array}{l}\text { Publications with at least one } \\
\text { foreign author }(\mathbf{M C P}=\text { Multiple } \\
\text { Country Publications })\end{array}$ & $\begin{array}{l}\text { Value } \\
\text { MCP }\end{array}$ \\
\hline México & 17 & 14 & 3 & 0.176 \\
\hline EUA & 13 & 10 & 3 & 0.231 \\
\hline Antigua & 2 & 2 & 0 & 0.000 \\
\hline Total & 32 & 26 & 6 & \\
\hline
\end{tabular}

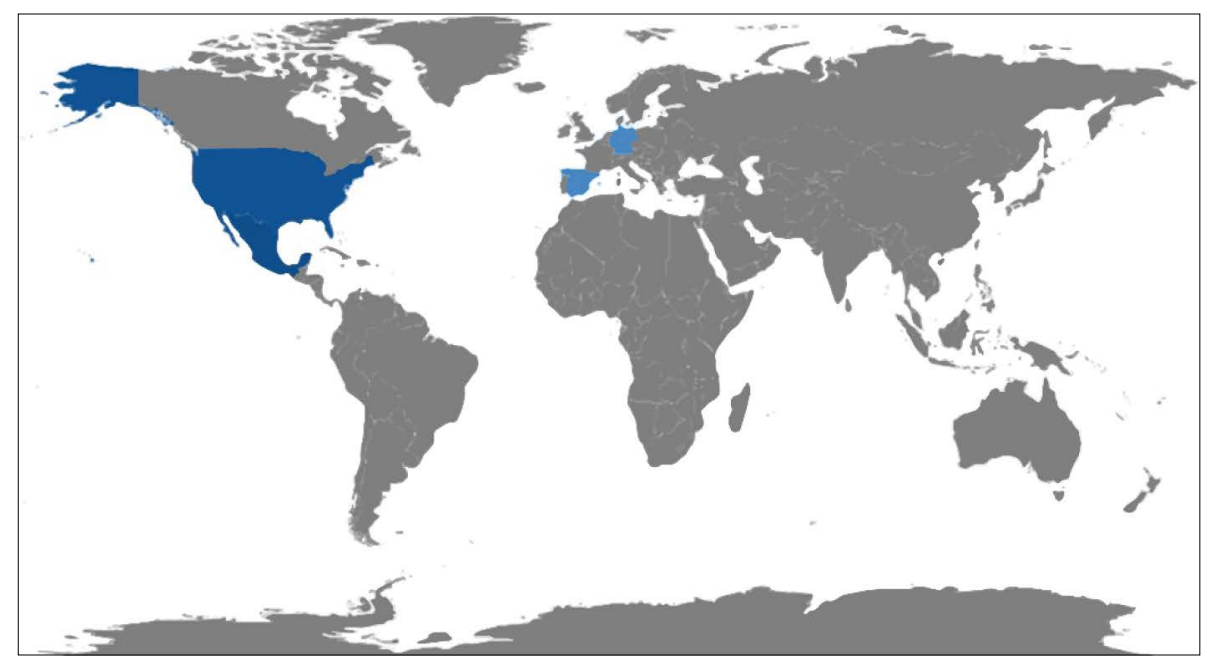

Figure 5. Scientific production by country.

In the Sankey diagram (http://sankey-diagram-generator.acquireprocure.com) shown in Figure 6, the association between authors is emphasized, citations of their works, and keywords. This allows to visually relate the intellectual roots represented by the authors, the citations that they use in their works and the content of the research, represented by the keywords.

\section{GONGLUSIONS}

This review revealed that the generated literature is mainly descriptive and qualitative. Advancing the knowledge base on the GBR will require a broader set of research methodologies, capable of documenting and proposing different strategies for conservation, development and social inclusion of its inhabitants. Successful shift towards sustainability in organizations and societies requires leadership to provide a vision, as well as establish direction and motivate people to move towards new goals. Therefore, sustainable leadership is emerging as a new domain of study within the field of management (Hallinger, 2020). Finally, the various findings in this research suggest that the research on the GBR should be encouraged, in addition to carrying out transdisciplinary research based on the expert 
knowledge of researchers who address the study of natural resources. Identifying major themes, trends, leaders, and core publications form the basis for identifying research gaps.

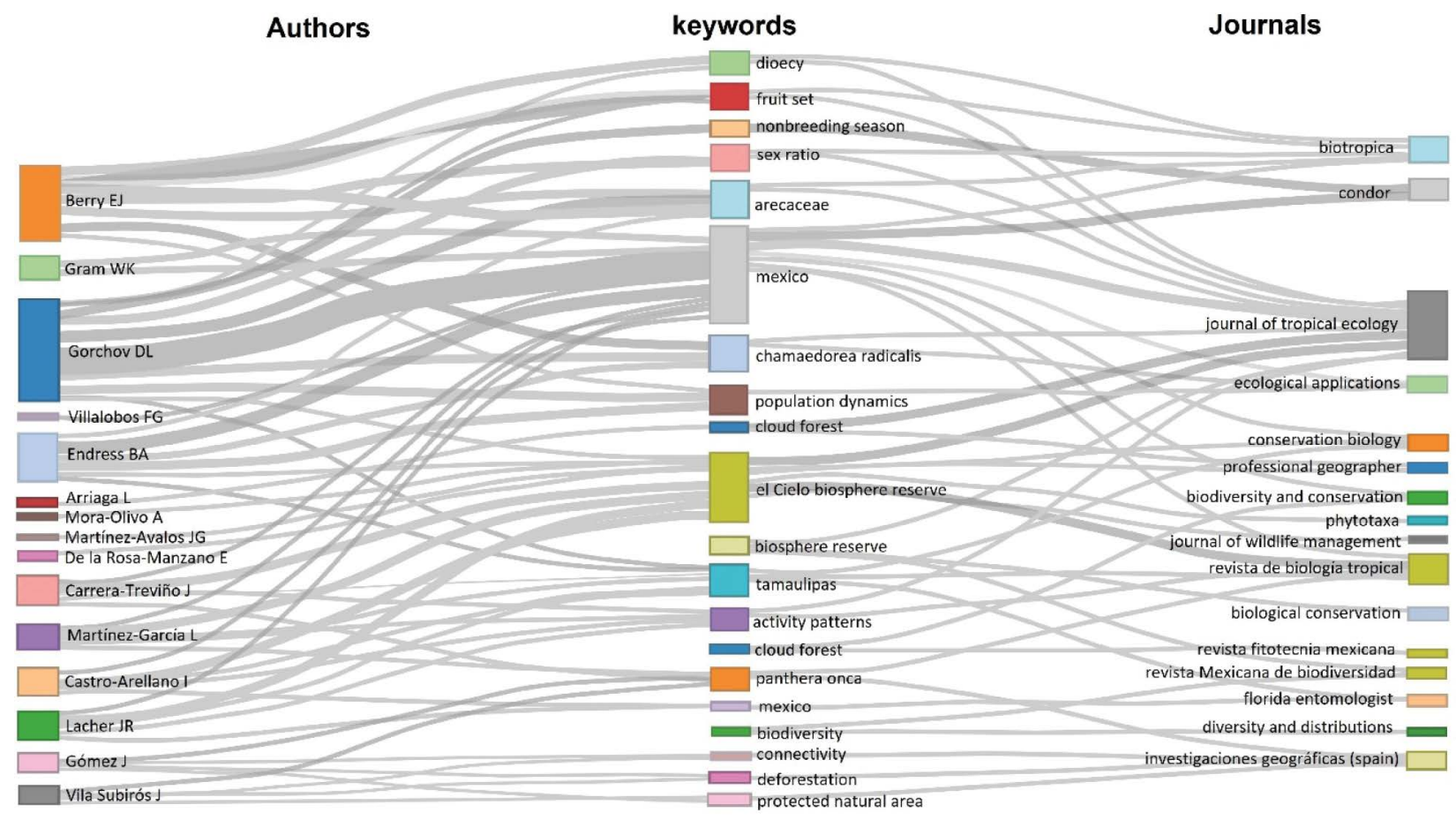

Figure 6. Intellectual roots and content of the research on the GBR.

\section{REFERENGES}

Alvarado, R. U. (2016). El crecimiento de la literatura sobre la ley de Bradford. Investigacion Bibliotecologica, 30(68), pp.51-72. Doi: 10.1016/j. ibbai.2016.02.003

East, H. (1983). Bradford revisited. Journal of Information Science, 7(3), pp.127-129. Doi: 10.1177/016555158300700307

Fahrig, L., Baudry, J., Brotons, L., Burel, F. G., Crist, T. O., Fuller, R. J., Sirami, C., Siriwardena, G. M., \& Martin, J. L. (2011). Functional landscape heterogeneity and animal biodiversity in agricultural landscapes. Ecology Letters, 14(2), pp.101-112. Doi: 10.1111/j.14610248.2010.01559.x

Fischer, J., \& Lindenmayer, D. B. (2007). Landscape modification and habitat fragmentation: A synthesis. Global Ecology and Biogeography, 16(3), pp.265-280. Doi:10.1111/j.1466-8238.2007.00287.x

Gazni, A., Sugimoto, G. R., \& Didegah, F. (2012). Mapping world scientific collaboration: Authors, institutions, and countries. Journal of the American Society for Information Science and Technology, 63(2), pp.323-335. Doi:ps://doi.org/10.1002/asi.21688

Giehl, E. L. H., Moretti, M., Walsh, J. C., Batalha, M. A., \& Cook, C. N. (2017). Scientific evidence and potential barriers in the management of Brazilian protected areas. PLoS ONE, 12(1), pp.1-12. Doi: 10.1371/journal.pone.0169917

Hallinger, P. (2020). Science mapping the knowledge base on educational leadership and management from the emerging regions of Asia, Africa and Latin America, 1965-2018. Educational Management Administration and Leadership, 48(2), pp.209-230. Doi: $10.1177 / 1741143218822772$

Hallinger, P., \& Suriyankietkaew, S. (2018). Science Mapping of the Knowledge Base on Sustainable Leadership, 1990-2018. Sustainability (Switzerland), 10(12), pp.1-22. Doi: 10.3390/su10124846

Hirsch, J. E. (2005). An index to quantify an individual's scientific research output. Proceedings of the National Academy of Sciences of the United States of America, 102(46). Doi:10.1073/pnas.0507655102

Khasseh, A. A., Soheili, F., Moghaddam, H. S., \& Chelak, A. M. (2017). Intellectual structure of knowledge in iMetrics: A co-word analysis. Information Processing and Management, 53(3), pp.705-720. Doi: 10.1016/j.ipm.2017.02.001

López, A., \& Sassone, A. B. (2019). The Uses of Herbaria in Botanical Research. A Review Based on Evidence From Argentina. Frontiers in Plant Science, 10(November), 1-10. Doi:10.3389/fpls.2019.01363

Lotka, A. J. (1926). The frequency distribution of scientific productivity. Journal of the Washington Academy of Sciences, 16(12), pp.317-323. http://www.jstor.org/stable/24529203 
R CoreTeam (2016). (n.d.). R Core Team (2016) R A Language and Environment for Statistical Computing. R Foundation for Statistical Computing, Vienna, Austria. - References - Scientific Research Publishing. Retrieved November 5, 2020, from https://www.scirp.org/ (S(lz5mqp453edsnp55rrgjct55))/reference/ReferencesPapers.aspx?ReferenceID=2010931

Topp, E. N., \& Loos, J. (2019). Fragmented Landscape, Fragmented Knowledge: A Synthesis of Renosterveld Ecology and Conservation. Environmental Conservation, 46(2), pp.171-179. Doi:10.1017/S0376892918000498

Tscharntke, T., Tylianakis, J. M., Rand, T. A., Didham, R. K., Fahrig, L., Batáry, P., Bengtsson, J., Clough, Y., Crist, T. O., Dormann, C. F., Ewers, R. M., Fründ, J., Holt, R. D., Holzschuh, A., Klein, A. M., Kleijn, D., Kremen, C., Landis, D. A., Laurance, W., ... Westphal, C. (2012). Landscape moderation of biodiversity patterns and processes - eight hypotheses. Biological Reviews, 87(3), pp.661-685. Doi: $10.1111 /$ j.1469-185X.2011.00216.x

URBIZAGASTEGUI, R. (1999). La ley de Lotka y la literatura de bibliometría. Investigación Bibliotecológica: Archivonomía, Bibliotecología e Información, 13(27), 125-141. Doi:10.22201/iibi.0187358xp.1999.27.3913

Wagner, C. S., Whetsell, T. A., \& Leydesdorff, L. (2017). Growth of international collaboration in science: revisiting six specialties. Scientometrics, 110(3), pp.1633-1652. Doi:10.1007/s1 1192-016-2230-9

Zupic, I., \& Čater, T. (2015). Bibliometric Methods in Management and Organization. Organizational Research Methods, 18(3), pp.429-472. Doi: $10.1177 / 1094428114562629$ 